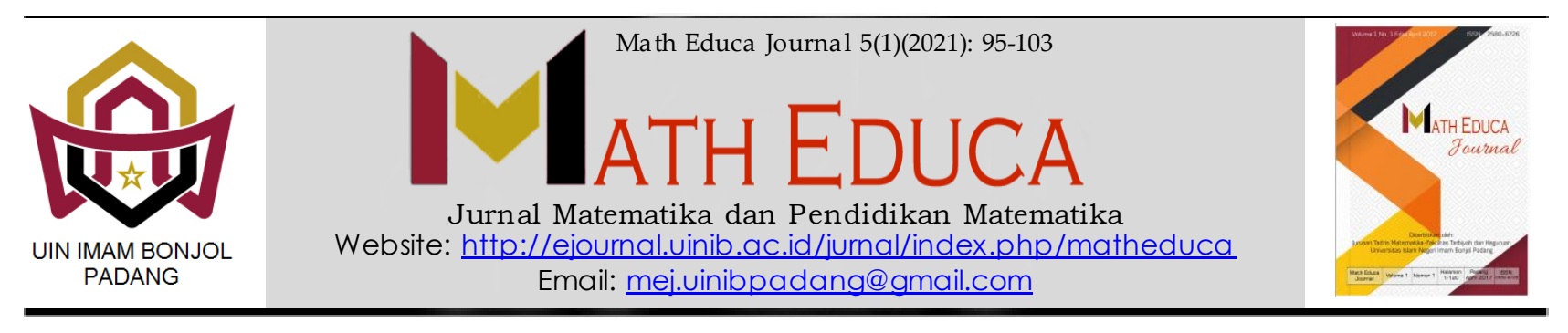

\title{
Hasil Evaluasi Kelompok Kecil Bahan Ajar Mata Kuliah Statistika Matematika Berbasis Pemecahan Masalah Serta Bernuansa Islami
}

\author{
'Nita Putri Utami*, ${ }^{2}$ Muhammad Kosim \\ 1,2 Universitas Islam Negeri Imam Bonjol Padang \\ E-mail: ' $\underline{\text { nitautami@uinib.ac.id, } 2 \text { muhammadkosim@uinib.ac.id }}$
}

Received: February 2021; Accepted: March 2021; Published: April 2021

\begin{abstract}
Tadris Mathematics is one of the study programs at UIN IB Padang with the vision "To produce character, professional and competitive mathematics education graduates in 2037". In order for this vision to be realized, of course there must be interesting interactions between lecturers and students in lectures. Meanwhile, the reality that occurs in lectures, there are still many students who are passive and result in many student scores that have not passed after taking the exam. One of the ways that a lecturer can do to overcome this problem is by developing Mathematical Statistics teaching materials based on problem solving and Islamic nuances. The formulation of the problem in this research is how the process and results of the development of Mathematics Statistics Subject Teaching Materials Based on Problem Solving and Practical Islamic Nuances in small group evaluations. This research is a development research with the Plomp development model using Tesmer's formative evaluation. Data collection techniques using practicality questionnaires from the teaching materials developed. From the results of the study, it was obtained a value of $79 \%$ with practical criteria that had been developed through a small group trial process.
\end{abstract}

Keywords: Problem solving, islamic nuances, small group evaluation

\begin{abstract}
Abstrak
Tadris Matematika merupakan salah satu prodi yang terdapat di UIN IB Padang dengan visi "Menghasilkan lulusan pendidikan matematika yang berkarakter, profesional dan kompetitif pada Tahun 2037". Agar visi tersebut terwujud tentunya harus terjadi interaksi yang menarik antara dosen dan mahasiswa dalam perkuliahan. Sedangkan kenyataan yang terjadi pada perkuliahan, masih banyak ditemui mahasiswa yang pasif dan mengakibatkan nilai mahasiswa banyak belum lulus setelah mengikuti ujian. Salah satu cara yang dapat dilakukan seorang dosen untukmengatasi masalah ini yaitu dengan mengembangkan bahan ajar Statistika Matematika Berbasis Pemecahan Masalah serta Bernuansa Islami. Rumusan masalah pada penelitiam ini bagaimana praktikalitas Bahan Ajar Mata Kuliah Statistika Matematika Berbasis Pemecahan Masalah Serta Bernuansa Islami pada evaluasi kelompok kecil. Penelitian ini merupakan penelitian pengembangan dengan model pengembangan Plomp menggunakan evaluasi formatif Tesmer. Teknik pengumpulan data dengan menggunakan angket praktikalitas dari bahan ajar yang dikembangkan. Dari hasil penelitian diperoleh nilai $79 \%$ dengan kriteria praktis untuk Bahan Ajar yang telah dikembangkan melalui proses uji coba kelompok kecil.
\end{abstract}

Kata kunci: Pemecahan masalah, nuansa islami, evaluasi kelompok kecil

\footnotetext{
${ }^{*}$ Corresponding author.

Peer review under responsibility UIN Imam Bonjol Padang.

(C) 2021 UIN Imam Bonjol Padang. All rights reserved.

p-ISSN: $2580-6726$

e-ISSN: 2598-2133
} 


\section{PENDAHULUAN}

Mahasiswa diharapkan aktif dalam perkuliahan. Mahasiswa juga dituntut kreatif mengelurkan ide-ide untuk menemukan dan memecahkan permasalahan yang ada pada perkuliahan. Jadi dosen hanya fasilitator saja dalam perkuliahan, perkuliahan lebih di dominasi mahasiswa agar terlaksana pembelajaran bermakna. Salah atu kondisi perkuliahan agar mahasiswa aktif dengan disediakan bahan ajar.

Bahan ajar yang menarik dapat dirancang oleh dosen yang mengampu mata kuliah. Akantetapi berdasarkan hasil observasi di lapangan pada jurusan Tadris Matematika UIN IB Padang, masih belum tersedianya bahan ajar yang memotivasi siswa untuk aktif dalam perkuliahan, salah satunya mata kuliah Statistika Matematika. Statistika Matematika merupakan salah satu mata kuliah seharusnya memiliki bahan ajar yang menuntut mahasiswa kreatif serta bekerjasama.

Salah satu mata kuliah yang materinya banyak digunakan untuk mengajar setelah menjadi guru yaitu Statistika Matematika. Selain itu juga banyak diaplikasikan materi kuliah dalam pembuatan tugas akhir. Mata kuliah dengan bobot 3 sks dan materi yang sangat banyak yang akan dibahas serta proses perkuliahan yang monoton sehingga banyak mahasiswa yang mengeluh. Mahasiswa Tadris Matematika Angkatan 2015, mengungkapkan dengan banyaknya materi dalam perkuliahan, perkuliahan kurang berkesan dan banyak tidak mengerti. Selain itu dosen lebih mendominasi dalam dibandingkan mahasiswa dalam proses pembelajaran. Akibatnya mahasiswa cendrung hanya menerima informasi yang diberikan dosen. Seharusnya, mahasiswa menemukan Konsep materi sendiri tanpa diberi tahu dosen melalui pemecahan masalah matematika yang dirancang dosen dikaitkan dengan Nilai Islam. Masalah yang diberikan merupakan masalah matematika yang berkaitan dengan nilai-nilai agama yang bisa diajarkan juga ketika mejadi seorang guru. Dengan memecahkan masalah matematika yang bernuansa islami dapat juga digunakan alumni Universitas Islam Negeri ketika sudah menjadi guru.

Akibat kurang efektifnya perkuliahan lebih dari sebagian mahasiswa memperoleh hasil belajar yang rendah. Dengan kata lain, pada mata kuliah Statistika Matematika masih banyak nilai mahasiswa yang belum lulus setelah mengikuti ujian. Temuan lain, dengan masalah yang sama yaitu mahasiswa cendrung hanya menerima saja dari penjelasan dan catatan dosen yang mengakibatkan juga banyak yang belum tuntas oleh Dian Nataria Oktaviani, dkk (2014). Selain itu, Yenni (2017) juga menemukan bahwa mahasiswa beranggapan mata kuliah statistika mata kuliah yang menakutkan dan melelahkan yang berakibat rendahnya nilai ujian. Dapat disimpulkan ternyata juga ditemukan masalah yang sama.

Dosen bertanggung jawab merancang bahan ajar yang dapat membantu dan mempermudah mahasiswa dalam perkuliahan. Salah satu yang dapat dirancang yaitu Bahan Ajar Mata Kuliah Statistika Matematika Berbasis Pemecahan Masalah Serta Bernuansa Islami. Bahan ajar ini dikembangkan dengan menggunakan modifikasi pemecahan masalah polya dengan masalah materi matematika yang dikaitkan dengan nilai Islam.

Ada empat tahapan pemecahan masalah yaitu memahami masalah, merencanakan penyelesaian masalah, melakukan perhitungan dan memeriksa kembali proses dan hasil (Polya dalam Susanto, 2013). Tiga tahapan polya yang diintegrasikan dengan nilai islami yaitu dengan diberikan masalah Islami dan diminta mahasiswa memahami masalah tersebut, kemudian mahasiswa diarahkan 
merencanakan penyelesaian masalah, dan melakukan perhitungan terhadap penyelesaian masalah Islami.

Proses memadukan nilai-nilai tertentu dengan sebuah konsep lain sehingga menjadi suatu kesatuan yang koheren dan tidak bisa dipisahkan atau proses pembauran hingga menjadi satu kesatuan yang utuh dan bulat (Chaerul, 2013:1) merupakan Integrasi nilai dalam pembelajaran. Jika mengintegrasi nilai Islam dalam Matematika, maka dalam pembelajaran matematika tersebut semua kegiatan dan aktivitas belajar matematika memuat nilai-nilai Islamnya.Dalam penelitian yang dilakukan, semua masalah yang akan dipecahkan mahasiswa dalam menemukan konsep matematika merupakan masala Islami.

Insan kamil adalah manusia yang mempunyai wajah Qur'ani, tercapainya insan yang memiliki dimensi religius, budaya dan ilmiah menurut Muhaimin dalam Ramayulis (2002:55). Dosen matematika juga bertanggung jawab terhadap mahasiswa yang nantinya lulusan UIN IB Padang memberikan ilmu matematika yang berkaitan dengan Islam.

Berdasarkan penjelasan diatas maka rumusan masalah pada penelitian ini bagaimana praktikalitas Bahan Ajar Mata Kuliah Statistika Matematika BerbasisPemecahan Masalah Serta Bernuansa Islami yang praktis pada evaluasi kelompok kecil. Sehingga tujuan penelitian ini adalah untuk mengetahui praktikalitas Bahan Ajar Mata Kuliah Statistika Matematika Berbasis Pemecahan Masalah Serta Bernuansa Islami pada evaluasi kelompok kecil.

\section{METODE PENELITIAN}

\section{Jenis Penelitian}

Model pengembangan yang digunakan diadaptasi dari Model Plomp. Ada 3 tahap, yaitu tahap investigasi awal, tahap pengembangan dan tahap penilaian (Plomp and Nieveen, 2013 :30) (Research and
Development).Putra (2012: 67) .Pada tulisan ini hanya akan dibahas pada fase pengembangan untuk evaluasi kelompok kecil saja terhadap bahan ajar yang dikembangkan.

\section{Waktu dan Tempat Penelitian}

Penelitian dilakukan pada Kelas B semester 5 Tadris Matematika tahun Pelajaran 2019/2020.

\section{Subyek Penelitian}

Kelompok kecil yang diambil dari mahasiswa Tadris Matematika Semester V merupakan subyek pada penilitian.

\section{Prosedur Penelitian}

Adapun prosedur pada penelitian ini dilakukan dengan cara berikut

\section{Tahap Investigasi Awal}

Analisis kebutuhan, analisis kurikulum, analisis mahasiswa dan analisis konsep, yang berhubungan dengan bahan ajar yang akan dikembangkan merupakan prosedur pada tahap ini.

\section{Tahap Pengembangan}

Berdasarkan hasil tahap investigasi awal, kemudian dikembangkan bahan ajar, setelah bahan ajar dikembangakan akan dilakukan evaluasi formatif untuk menghasilkan bahan ajar yang valid dan praktis. Evaluasi formatif yang digunakan dalam penelitian ini adalah evaluasi sendiri, tinjauan ahli, evaluasi satu-satu dan evaluasi kelompok kecil. Pada tulisan ini hanya dibahas evaluasi kelompok kecil.

Analisis data angket kelompok kecil dilakukan dengan beberapa langkah sebagai berikut.

a. Memberikan skor jawaban dengan kriteria berdasarkan skala Likert yang dimodifikasi da-ri Riduwan (2012:27) dengan 4 alternatif yang telah ditentukan.

b. Menentukan jumlah skor dari masingmasing responden dengan 
menjumlahkan semua skor yang diperoleh dari masing-masing indikator.

c. Penentuan nilai angket dengan cara: Nilai angket (kognitif/afektif/psikomotor)

$$
=\frac{\text { jumlahskoryangdiperoleh }}{\text { jumlahskortertinggi }} \times 100
$$

Memberikan penilaian praktikalitas dengan kriteria seperti yang dikemukakan oleh Riduwan (2012:29) yang telah dimodifikasi.

Tabel 1. Kriteria Praktis

\begin{tabular}{ll}
\hline Nilai & Kriteria \\
\hline $0-20$ & Tidak Praktis \\
\hline $21-40$ & Kurang Praktis \\
\hline $41-60$ & Cukup Praktis \\
\hline $61-80$ & Praktis \\
\hline $81-100$ & Sangat Praktis \\
\hline
\end{tabular}

\section{HASIL PENELITIAN DAN PEMBAHASAN}

Setelah produk diujicobakan pada kelompok kecil dan dilakukan wawancara serta diberikan angket praktikalitas diperoleh bahwa Bahan Ajar yang digunakan dalam proses perkuliahan sangat menfasilitasi mahasiswa untuk aktif dan menemukan sendiri konsep dari masalah matematika yang Islami. Hal ini disebabkan karena pembelajaran yang dilakukan menuntut mahasiswa untuk memecahkan masalah-masalah yang ada pada bahan ajar. Masalah-masalah yang dipilih merupakan masalah Islami yang berkaitan dengan materi yang dipelajari. Pada setiap awal pertemuan diberikan Ayat Al-Quran yang menuntut mahasiswa untuk menafsrikan makna ayat tersebut tentunya suatu proses pembelajaran yang berbeda dan menarik. Selain menafsirkan, mahasiswa juga diminta untuk memahami kaitan antara ayat tersebut dengan materi yang akan dipelajari.

Uji coba kelompok kecil dapat dilakukan setelah revisi terhadap saran dan kritikan dari evaluasi satu-satu oleh tiga orang mahasiswa tentang Bahan Ajar, kemudian dilanjutkan uji coba kelompok kecil/ small group. Uji coba kelompok kecil diberikan kepada 9 orang mahasiswa yang terdiri atas 3 orang kemampuan tinggi, 3 orang kemampuan rendah dan 3 orang kemampuan sedang. Pada uji coba kelompok kecil ini, peneliti mengajar sendiri sesuai dengan kegiatan pembelajaran pada RKPS. Dalam kegiatan pembelajaran, kelas dibagi menjadi 3 kelompok yang masingmasing kelompok heterogen terhadap kemampuan rendah, sedang dan tinggi. Data diperoleh dengan memberikan angket dan wawancara terhadap mahasiswa di setiap pertemuan setelah proses pembelajaran berlangsung. Pelaksanaan evaluasi kelompok kecil dapat dilihat pada Gambar 1.

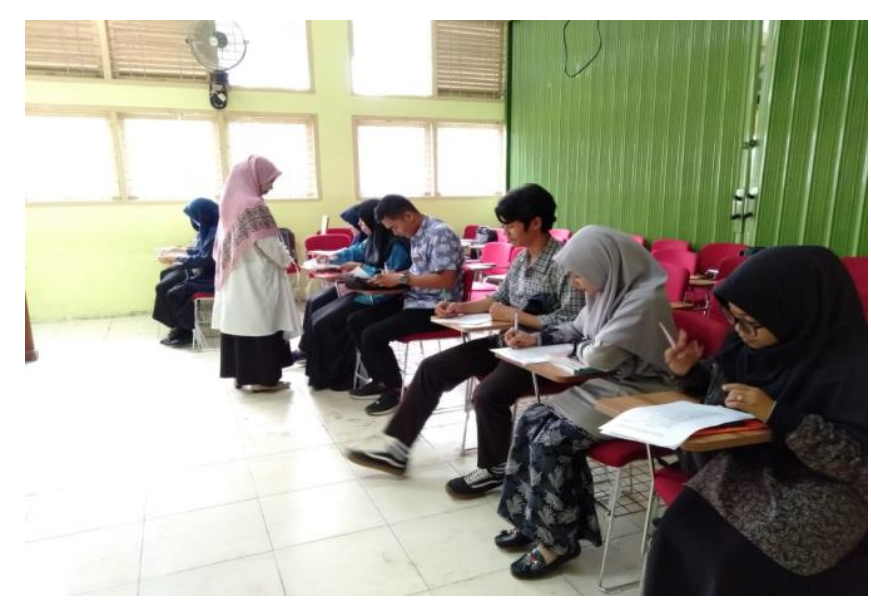

Gambar 1. Pelaksanaan evaluasi kelompok kecil

Hasil rata-rata angket praktikalitas dari uji coba kelompok kecil diperoleh $72 \%$ untuk pertemuan I dengan kriteria praktis. Artinya bahan ajar sudah layak digunakan pada kelompok kecil untuk pertemuan I . Akantetapi Setelah bahan ajar digunakan, masih ditemukan beberapa soal yang rancu sehingga mahasiswa kebingungan dalam menyelesaikan. Soal yang rancu diperbaiki langsung ketika proses pembelajaran berlangsung. Sedangkan rata-rata angket praktikalitas dari uji coba kelompok kecil diperoleh $76 \%$ untuk pertemuan II dengan kriteria praktis. Jadi terdapat peningkatan kepraktisan dari Bahan Ajar digunakan pada kelompok kecil untuk pertemuan II. Kesalahan yang ditemukan yaitu terdapat satu soal yang keliru sehingga mahasiswa sulit dalam menyelesaikan. Soal yang keliru langsung diperbaiki ketika proses pembelajaran berlangsung dan mahasiswapun bisa menyelesaikannya. 
Rata-rata angket praktikalitas dari uji coba kelompok kecil diperoleh $80 \%$ untuk pertemuan III dengan kriteria praktis. Artinya terjadi peningkatan nilai praktikalitas dari pertemuan-pertemuan sebelumnya. Setiap perbaikan pada uji coba sebelumnnya, juga menjadi persiapan yang lebih matang dari peneliti, sehingga terjadi peningkatan di setiap pertemuan. Dari empat komponen praktikalitas, 3 komponen sudah memenuhi kriteri sangat praktis dan 1 komponen dengan kriteria praktis. Setelah bahan ajar digunakan, ternyata juga ditemukan satu soal yang salah sehingga mahasiswa tidak dapat menyelesaikannya. Setelah soal yang salah diperbaiki, mahasiswa bisa langsung mencoba mencari penyelesaian.

Berdasarkan hasil wawancara dengan mahasiswa mereka mengungkapkan bahwa bahan ajar ini sangat menarik dan bermanfaat karena dapat juga digunakan pada saat telah menjadi guru. Bahan ajar ini juga menambah wawasan keislaman mahasiswa. Dan yang paling penting, bahan ajar ini menfasilitasi mahasiswa untuk aktif dalam perkuliahan dengan menemukan konsep dari aktivitas menyelesaikan masalah-masalah Islami. Serta beberapa saran untuk bahan ajar, diantaranya akan lebih baik bahan ajar menggunakan gambar, bahan ajar dilengkapi dengan contoh, dan soal latihan lebih banyak lagi.

Tabel 2. Nilai Praktikalitas Pertemuan I

\begin{tabular}{llcl}
\hline $\mathbf{N}$ & \multicolumn{1}{|}{$\begin{array}{c}\text { Komponen } \\
\text { O }\end{array}$} & $\begin{array}{c}\text { Praktikalitas } \\
\text { Praktikalitas }\end{array}$ & Kriteria \\
\hline 1. & $\begin{array}{l}\text { Proses } \\
\text { Penggunaan }\end{array}$ & $75 \%$ & Praktis \\
\hline 2. & $\begin{array}{l}\text { Kemudahan } \\
\text { Penggunaan }\end{array}$ & $74 \%$ & Praktis \\
\hline 3. & Waktu & $72 \%$ & Praktis \\
\hline 4. & Daya Tarik & $67 \%$ & Praktis \\
\hline
\end{tabular}

Untuk komponen daya tarik mahasiswa diperoleh hanya $67 \%$ untuk pertemuan I dan merupakan komponen praktikalitas yang memiliki nilai paling rendah diantara komponen lainnya. Hal ini disebabkan proses pembelajaran yang digunakan merupakan bentuk yang baru dan menurut hasil wawancara, beberapa mahasiswa agak malas mencari terjemahan dari Ayat. Akantetapi ada bebepa mahasiswa yang juga mengungkapkan, bahwa bahan ajar ini menarik karena mereka harus belajar agama dan matematika sekaligus. Selain itu,bahan ajar ini juga memiliki warna-warna dan tata letak yang menarik. Sejalan dengan itu menurut Dzulkifli dan Mustafar (2013:3) bahwa "warna sangat efektif digunakan dalam pembelajaran dan pengaturan pendidikan." Hal ini diperkuat oleh Gaines dan Curry (2011: 54) menyatakan bahwa "warna memiliki kemampuan untuk mempengaruhi perhatian, prilaku, dan prestasi peserta didik." Berikut hasil revisi bahan ajar dari masukan evaluasi kelompok kecil.

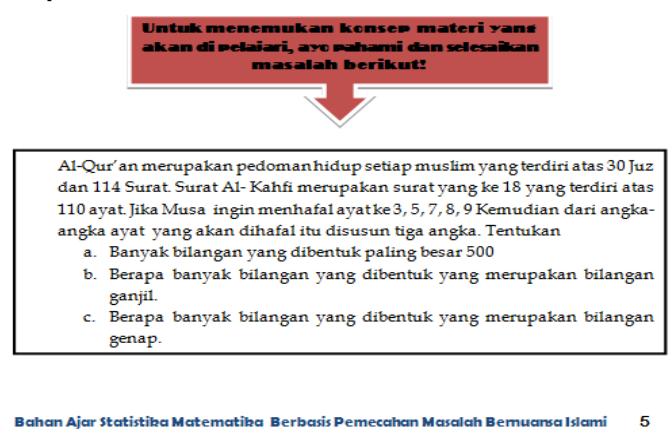

B. PERMUTASI

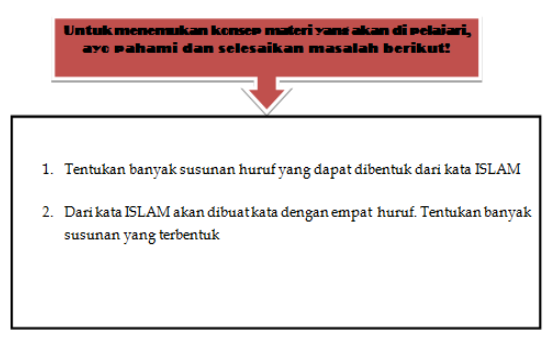

Gambar 2. Hasil Revisi Pertemuan I Evaluasi Kelompok Kecil 


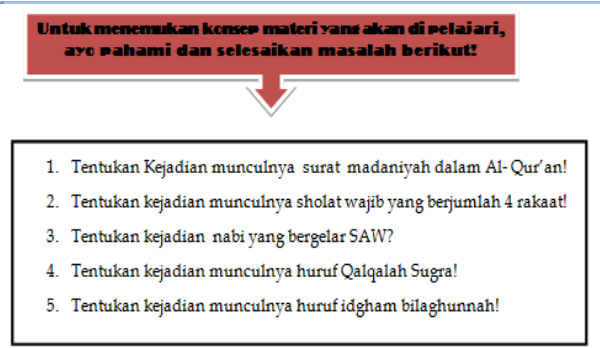

Bahan Ajar Statistika Matematiba Berbasis Pemecahan Masalah Bemuarra lssami 24

\section{Gambar 3. Hasil Revisi Pertemuan II Pada Evaluasi Kelompok Kecil}

Tabel 3. Nilai Praktikalitas Pertemuan II

\begin{tabular}{llcl}
\hline No & $\begin{array}{l}\text { Komponen } \\
\text { Praktikalitas }\end{array}$ & $\begin{array}{c}\text { Praktikalitas } \\
(\%)\end{array}$ & Kriteria \\
\hline 1. & $\begin{array}{l}\text { Proses } \\
\text { Penggunaan }\end{array}$ & $83 \%$ & $\begin{array}{l}\text { Sangat } \\
\text { Praktis }\end{array}$ \\
\hline 2. & $\begin{array}{l}\text { Kemudahan } \\
\text { Penggunaan }\end{array}$ & $79 \%$ & Praktis \\
\hline 3. & Waktu & $72 \%$ & Praktis \\
\hline 4. & Daya Tarik & $68 \%$ & Praktis \\
\hline
\end{tabular}

Komponen proses penggunaan bahan ajar $83 \%$ untuk pertemuan II dengan kriteria sangat praktis merupakan komponen praktikalitas yang memiliki nilai paling tinggi diantara komponen lainnya. Hal ini disebabkan dalam proses pembelajaran mahasiswa sendiri memecahkan masalah Islami dalam menemukan konsep. Berdasarkan hasil wawancara mahasiwa mengungkapkan "Materi yang diajarkan sangat menarik dan meningkatkan spritual mahasiswa dalam mempelajari bukunya". Mahasiwa juga mengungkapkan soal yang dipecahkan merupakan soal yang berhubungan langsung dengan materi Islami yang telah dipelajari.

\section{G. PeluangKejadian Saling Lepas}

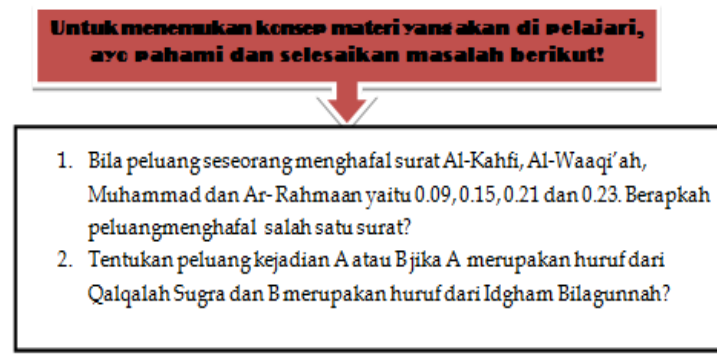

Bahan Ajar Statistika Matematika Berbasis Pemecahan Masalah Bemuansa Islami $\quad 39$

\section{Gambar 4. Hasil Revisi Pertemuan III Pada Evaluasi Kelompok Kecil}

Tabel 4. Nilai Praktikalitas Pertemuan III

\begin{tabular}{llcc}
\hline $\mathbf{N}$ & $\begin{array}{l}\text { Komponen } \\
\text { o }\end{array}$ & $\begin{array}{c}\text { Praktikalitas } \\
\text { itas (\%) }\end{array}$ & Kriteria \\
\hline 1. & $\begin{array}{l}\text { Proses } \\
\text { Penggunaan }\end{array}$ & $85 \%$ & $\begin{array}{l}\text { Sangat } \\
\text { Praktis }\end{array}$ \\
\hline 2. & $\begin{array}{l}\text { Kemudahan } \\
\text { Penggunaan }\end{array}$ & $82 \%$ & Sangat Praktis \\
\hline 3. & Waktu & $83 \%$ & Sangat Praktis \\
\hline 4. & Daya Tarik & $70 \%$ & Praktis \\
\hline
\end{tabular}

Komponen praktikalitas daya tarik mahasiswa hanya $70 \%$ untuk pertemuan III terjadi peningkatan dibandingkan dua pertemuan sebelumnya, hal ini disebakan mahasiswa sudah mulai terbiasa menggunakan bahan ajar. Berdasarkan hasil wawancara, mereka mengungkapkan bahwa bahan ajar sangat menarik digunakan karena mereka aktif dalam proses pembelajaran dan dapat bekerjasama dengan teman dalam kelompok untuk menemukan konsep materi. Artinya bahan ajar dapat menfasilitasi mahasiswa dalam mencapai tujuan pembelajaran. Sejalan dengan Lestari (2013:2) pengembangan bahan ajar didasarkan pada konsep desain pembelajaran yang berdasarkan pada suatu kompetensi atau untuk mencapai tujuan pembelajaran. 
Nita PutriUtami, M.Pd

I

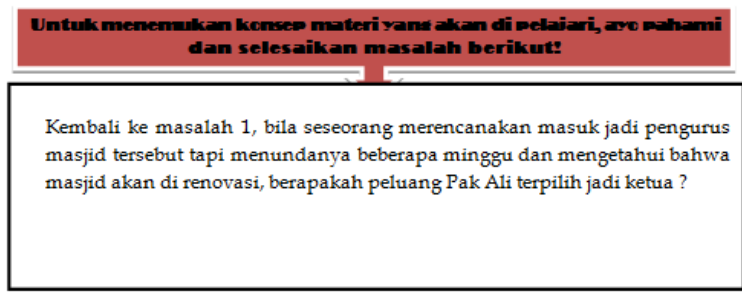

Selesaikan masalah di atas

suai denøan lanskal-

langkah berikut:

Gambar 5. Hasil Revisi Pertemuan IV Pada Evaluasi Kelompok Kecil

Tabel 5. Nilai Praktikalitas Pertemuan IV, V, VI

\begin{tabular}{llcc}
\hline \multicolumn{3}{c}{ Pertemuan IV } \\
\hline 1. & $\begin{array}{l}\text { Proses } \\
\text { Penggunaan }\end{array}$ & $81 \%$ & Sangat praktis \\
\hline 2. & $\begin{array}{l}\text { Kemudahan } \\
\text { Penggunaan }\end{array}$ & $78 \%$ & Praktis \\
\hline 3. & Waktu & $81 \%$ & Sangat praktis \\
\hline 4. & Daya Tarik & $74 \%$ & Praktis \\
\hline \multicolumn{4}{c}{ Pertemuan V } \\
\hline 1. & Proses & \\
\hline & Penggunaan & Sangat Praktis \\
\hline 2. & Kemudahan & $73 \%$ & Praktis \\
& Penggunaan \\
\hline 3. & Waktu & $81 \%$ & Sangat Praktis \\
\hline 4. & Daya Tarik & $78 \%$ & Praktis \\
\hline
\end{tabular}

\section{Pertemuan VI}

\begin{tabular}{llll}
\hline 1. & $\begin{array}{l}\text { Proses } \\
\text { Penggunaan }\end{array}$ & $88 \%$ & Sangat Praktis \\
\hline & & \\
\hline
\end{tabular}

2. Kemudahan $81 \%$ Sangat Praktis
Penggunaan

\begin{tabular}{clrr}
\hline 3. & Waktu & $83 \%$ & Sangat Praktis \\
\hline 4. & Daya Tarik & $81 \%$ & Sangat Praktis \\
\hline \multicolumn{4}{c}{ Pertemuan VII }
\end{tabular}

\begin{tabular}{llll}
\hline 1. & $\begin{array}{l}\text { Proses } \\
\text { Penggunaan }\end{array}$ & $92 \%$ & Sangat Praktis \\
\hline
\end{tabular}

\begin{tabular}{|c|c|c|c|}
\hline 2. & $\begin{array}{l}\text { Kemudahan } \\
\text { Penggunaan }\end{array}$ & $81 \%$ & Sangat Praktis \\
\hline & Waktu & $81 \%$ & $\begin{array}{l}\text { Sangat } \\
\text { Praktis }\end{array}$ \\
\hline
\end{tabular}

\begin{tabular}{|c|c|c|}
\hline 4. Daya Tarik & $90 \%$ & Sangat Praktis \\
\hline $\begin{array}{c}\text { Nilai } \\
\text { Praktikalitas }\end{array}$ & $79 \%$ & Praktis \\
\hline
\end{tabular}

Rata-rata praktikalitas $78,5 \%$ dengan kriteria praktis untuk pertemuan IV. Terjadi penurunan nilai praktikalitas Bahan Ajar yang diujicobakan pada pertemuan IV dari pertemuan-pertemuan sebelumnya. Hal ini disebabkan, materi pertemuan keempat lebih sulit dibandingkan pertemuan-pertemuan sebelumnya. Setelah bahan ajar digunakan, ternyata juga ditemukan satu soal yang salah sehingga mahasiswa tidak dapat menyelesaikannya.

Rata-rata praktikalitas $80 \%$ (Praktis) untuk pertemuan kelima, keenam 83\% (sangat praktis) dan ketujuh 86\% (sangat praktis). Dari pertemuan awal smpai pertemuan terkahir bahan ajar diujicobakan terdapat peningkatan nilai praktikalitas, dan pada 2 pertemuan terakhir sudah memenuhi kriteria sangat praktis. Ini menunjukkan bahwa Bahan Ajar yang telah dikembangkan dapat digunakan pada mahasiswa dalam kelompok kecil.

\section{SIMPULAN DAN SARAN}

\section{Simpulan}

Hasil dari proses uji coba kelompok kecil terhadap Bahan Ajar yang telah dikembangkan dinyatakan praktis dengan nilai $79 \%$.

\section{Saran}

1. Dapat dilakukan ujicoba terbatas pada kelas terhadap bahan ajar yang telah dikembangkan agar lebih diketahui bagaimana praktikalitas untuk kelas dan efektivitas.

2. Hasil dari uji coba kelompok kecil dinyatakan praktis terhadap Bahan Ajar yang telah dikembangkan sehingga bahan ajar dapat digunakan dalam perkuliahan.

\section{REFERENSI}

Al-Quran Terjemahan. 2015. Depertemen Agama RI. Bandung: CV Darus Sunnah. 
Anita Nasution .(2016). "Pengembangan Modul Matematika Berbasis Masalah Untuk Meningkatkan Kemampuan Pemecahan Masalah Matematika Siswa" Jurnal Pendidikan dan Kependidikan FKIP Universitas Al-Wasliyah Labuhanba-tu.Vol 1 No 1 (2016). ISSN 2527-5295

Arikunto. 2013. Dasar-dasar Evaluasi Pendidikan Edisi 2. Jakarta: Bumi Aksara.

Depdiknas.2008. Panduan Pengembangan Bahan Ajar. Jakarta: Direktorat Jendral Ma-najemen Pendidikan Dasar dan Menen-gah.

Deswita,Hera.2014."Pengembangan Perangkat Pembelajaran Matematika Berbasis Masalah Untuk Kelas VII Sekolah Menen-gah Pertama".Tesis tidak diterbitkan. Padang: Program Pascasarjana UNP Padang.

Dian Nataria Oktaviani, dkk .(2014)."Pengembangan Modul Statistika Matematika I Berbasis Kontruktivisme Pada Pendidikan Matematika Universitas Pancasakti Tegal". Vol 8, No 13 (2014)

Dzulkifli, M.A. and Muhammad Faiz Mustafar. 2013. The Influence of Colour on Memory Performance: A Review. Malays J Med Sci. Volume 20, Number 2, 3-9.

Islamiyah, D. 2011. Peningkatan Prestasi Belajar Siswa dalam Memahami Bacaan Baha-sa Inggris Melalui Strategi Inkuiri di Kelas IVA Minu Ngingas Waru Sidoar-jo.Skripsi tidak diterbitkan. Surabaya: IAIN Sunan Ampel Surabaya.

Jalilehvand, M. 2012.The Effects of Text Length and Picture on Reading Comprehension of Iranian EFL Students.Asian Social Science, Vol. 8, No. 3, pp. 329-337.

Jeaniver, dkk. (2017). "Pengembangan Bahan Ajar Matematika Berbasis Masalah Berorien-tasi Pada Kemampuan Pemecahan Ma-salah Matematis dan Prestasi Belajar Matematika" dalam jurnal Indonesian Journal of Mathematics Education . Vol 1 No 1 (2018) p-ISSN 2654-3907, e-ISSN 2654-346X

Mukhlis Novandi, dkk.(2016). Pengembangan Bahan Ajar Matematika Berbasis Pemecahan Masalah Untuk Meningkatkan Kemampuan Penalaran Dan Koneksi Matematis Siswa SMP.dalam jurnal penelitian Pendidikan MIPA UMN AL Washliyah. Vol 1 No 1 (2016). ISSN 25029614.

Nanang Supriadi. (2015). Mengembangkan Kemampuan Koneksi Matematis Melalui Buku Ajar Elektronik Interaktif (BAEI) Yang Terintegrasi Nilai-Nilai Keislaman dalam Jurnal Pendidikan Matematika AlJabar UIN Raden Intan Lam-pung.Vol 6 No 1(2015).

Nisraeni, dkk .(2014).“Pengembangan Bahan Ajar Mata Kuliah Statistika Dasar Dengan Penerapan Model Kooperatif Tipe TPS (Think Pair Share) Melalui Program Lesson Study". Prosiding Seminar Nasional Universitas Cokroaminoto Palopo.Vol 1, No 1(2014).

Plomp, T dan N. Nieveen. 2013. Educational Design Research. Enshede: Netherlands InstituteFor Curriculum Development (SLO).

Putra, N. 2012.Research \&Development: Peneli-tian dan Pengembangan (Suatu Pengan-tar).Jakarta : Rajawali Press. 
Purwanto, N. 2009. Prinsip-prinsip dan Teknik Evaluasi Pengajaran. Bandung: Remaja Rosdakarya.

Rahman,Chaerul. Integrasi Nilai-Nilai Islam dalam Pembelajaran IPA di Sekolah.http://uai.ac.id.2013

Riduwan. 2015. Dasar-Dasar Statistika. Bandung: Alfabeta

Rochmad. 2011. Model Pengembangan Perangkat Pembelajaran Matematika. Artikel tidak diterbitkan. Semarang: UNNES.

Sholikatun Khasanah. (2015). "Pengembangan Bahan Ajar Matematika Berbasis Pendidikan Nilai Islam Pada Pokok Bahasan Himpunan Di Mts Negeri Mlinjon Klaten" dalam naskah publikasi Universitas Muhamadiyah Surakarta.
Suherman, Erman. dkk. 2003. Strategi Pembelaja-ran Matematika Kontemporer (revisi). Bandung: JICA-UPI.

Sukardi.2008. Evaluasi Pendidikan. Jakarta: Bumi Aksara.

Susanto, Ahmad. 2013. Teori Belajar dan Pembe-lajaran Di Sekolah Dasar.Jakarta: Pra-nada Media Group

Suyatman.2013. Pengembangan Bahan Ajar.Surakarta: FATABA Press IAIN Surakarta.

Walpole, Ronald E \& Myers, Raymond "\{H.1995.Ilmu Peluang Dan Statistika Untuk Insinyur Dan Ilmuan. Bandung: ITB

Yenni .(2017). "Pengembangan Bahan Ajar Statis-tika Untuk Mengembangkan Kemam-puan Pemahaman Matematis Mahasiswa Pendidikan Anak Usia Dini Pada Mata Kuliah Statistika" . Journal OfMa-thematics Education Science \& Tech-nology. Vol 2, No 1 (2017) . 